Página inicial: 290 - Página Final: 308

Tipo de Artículo: Revisión.

\title{
La vulnerabilidad de la mujer en la guerra y su papel en el posconflicto.
}

\author{
Woman's Vulnerability in the War and her Role in the Post-Conflict.
}

\author{
Por: José Alonso Andrade Salazar ${ }^{1}$, Libia Alvis Barranco ${ }^{2}$, Luz Karine Jiménez Ruiz ${ }^{3}$, Miladys \\ Paola Redondo Marín ${ }^{4}$ y Lida Rodríguez González ${ }^{5}$
}

Recibido: Junio de 2016 Revisado: noviembre de 2016 Aceptado: noviembre de 2016

\section{Resumen.}

Abordar la violencia contra la mujer en el marco del conflicto armado colombiano, y su papel en el postconflicto implicar hacer énfasis en los efectos de la violencia en las mujeres, la instrumentalización de su cuerpo, las secuelas psicológicas que el desplazamiento forzado genera, y su papel de restitución social. El papel femenino en el postconflicto es innegable y necesario para construir paz y paces, en este sentido experiencias de mediación muestran que cuando la mujer es parte de las negociaciones, los procesos de conciliación son más viables y efectivos.

Palabras Clave: conflicto armado, Colombia, desplazamiento forzado, violencia, violencia contra la mujer, violencia de género.

\begin{abstract}
.
Addressing violence against women, within the Colombian armed conflict framework and their role in the post-conflict, implies making emphasis on the effects of violence against women, the instrumentalization of their body, the psychological hardship produced by the forced displacement, and their role of social restitution. Women's role in the post-conflict is unquestionable and necessary in order to make Peace. In this sense, mediation experiences show that when women are part of negotiations, the conciliation processes are more feasible and effective.
\end{abstract}

Key words: Armed Conflict, Colombia, Forced Displacement, Violence, Violence against Women, Gender Violence.

\footnotetext{
${ }^{1}$ Psicólogo. Docente investigador. Universidad de San Buenaventura Medellín extensión armenia. Docente investigador del grupo interdisciplinario para el desarrollo y la acción dialógica (GIDPAD) y del grupo Estudios clínicos y sociales en psicología. Contacto: 211psicologia@gmail.com

2 Psicóloga, Directora Programa de Psicología Universidad Popular del Cesar. Magister en Prosocialidad y Logoterapia. Doctorando en Ciencias Políticas. Contacto: libiaalvis@gmail.com

3 Psicóloga, Docente Universidad Popular del Cesar. Magister en Gerencia del Talento Humano. Contacto: luzjimenez@,unicesar.edu.co

${ }_{4}$ Psicóloga, Docente Universidad Popular del Cesar. Especialista en Sistema de Calidad y Auditoría en Salud. Maestrante en Educación. Contacto: miladysredondo@unicesar.edu.co

5 Psicóloga, Especialista en Gerencia en Salud Ocupacional con Magíster En Educación. Coordinadora Académica Programa de Turismo Universidad Minuto de Dios, Bogotá. Contacto: lidarogo68@hotmail.com
} 


\section{Introducción.}

A medida que las prácticas implementadas en la guerra incrementan su letalidad generando mayor destrucción y pérdidas irreparables, la naturaleza de las relaciones entre géneros presenta modificaciones importantes, entre las que se encuentran: el cambio de roles entre hombre y mujer (Barros y Rojas, 2015), la viudez forzada, desconfianza en el otro, dificultades para reorganizar la vida afectiva con una nueva pareja (Garzón, 2005), perdida de la tradición oral, segregación de la memoria, extinción de creencias y de legados culturales entre otros aspectos (Andrade, 2011). En esta línea regular de cambios, las investigaciones han dado una mirada modesta a la especificidad del maltrato del cual la mujer es víctima mayoritaria, y aunque muchos resultados revelen dicha vulnerabilidad, la naturaleza descriptiva de los hallazgos, limita los acercamientos reales a la dinámica vivencial de las víctimas. Cabe anotar que los estudios han transitado paulatinamente hacia la caracterización de dicha vulnerabilidad, mostrando que la violencia contra la mujer (VCM) es programada, selectiva, y se encuentra indiscutiblemente determinada, motivo por el cual al referirse a la VCM se debe hablar en realidad, del conglomerado de acciones anulativas intencionales, teleológicas y mortales que afectan al género femenino, y que presentan una clara y directa intencionalidad destructiva.

En torno a ello es preciso anotar que en este trabajo la hipótesis que guía la reflexión es que las creencias negativas acerca del rol femenino, y la legitimidad del maltrato a la mujer en el conflicto armado y en su tránsito por diversos lugares de reasentamiento, se constituyen en elementos que mantienen y elevan su vulnerabilidad, y que son estos mismos factores los que ofrecen luces acerca del papel transformador de la mujer en el marco del postconflicto. Al respecto es importante mencionar que la Alta Comisionada de las Naciones Unidas para los Derechos Humanos (ACNUR, 2009a) afirma que en el marco del conflicto entre estado e insurgencias violentas en Colombia, los actores armados presentan fuertes inclinaciones a abusar de la intimidad y los derechos de la mujer, quien sufre una representativa afectación del derecho a la vida, la integridad física y desatención del deber de garantía, situación en la que no solo están involucrados los grupos insurgentes, sino también la fuerza pública. La entidad señala que se cuentan con pruebas para advertir el "aumento del número de casos de tratos crueles y degradantes contra mujeres y niñas por miembros del ejército" (ACNUR, 2009, p. 9), y de diversos actores armados que usan la fuerza para obtener beneficios de las mujeres a nombre de la guerra, o en función de sus intereses instrumentales.

Dicha circunstancia instala el conflicto en el plano del género femenino, al tiempo que ubica históricamente a la mujer en un escenario de vulnerabilidad innegable (Andrade, 2011). Para el Centro nacional de memoria histórica $(\mathrm{CNMH}, 2011)$, la vulnerabilidad de la mujer en los espacios de conflicto, migración y asentamiento es elevada, ya que los actores armados imponen restricciones y dejan secuelas emocionales de terror que persisten en las personas desplazadas aun cuando algunas condiciones de inseguridad se disminuyan. Así muchas mujeres sobrevivientes a la guerra pueden experimentar una gran tensión emocional, que en ocasiones puede ser descargada inapropiadamente con sus hijos, familiares y otros externos, constituyendo una fuente de conflicto y preocupación en la familia (Ordoñez, 2013; Segura, 2010; Andrade, 2010). La vida emocional de las mujeres desplazadas por la guerra es fluctuante, sin embargo los sentimientos y afectos negativos involucrados en su estado afectivo no son un factor principal de abordaje, puesto que la intensión vital se concentra en sobrevivir, escapar y proteger a su familia de peligros reales o posibles (Ruta Pacífica de las Mujeres - RPM, 2013); esta creencia negativa impresa en el desplazamiento per se, aumenta su estado de vulnerabilidad, dado que el

\begin{tabular}{l|l|l|l|l|l|l} 
AGO.USB & Medellín - Colombia & Vol. 17 No. 1 & PP 1 - 323 & enero - junio & 2017 & ISSN: 16578031
\end{tabular} 
equilibrio relativo en la salud mental es un componente primordial para asegurar procesos de ajuste psicosocial y de asentamiento territorial más exitosos.

Estudios exponen que el conflicto armado revela en el plano de la VCM, una intencionalidad destructiva que, a nivel individual y grupal, expresa las desigualdades en las relaciones de poder y de acceso a beneficios y derechos de las mujeres, tornando la violencia unidireccional, patriarcal, teleológicamente destructiva e instrumental (Archila, 2014; Cadavid, 2014; Barros y Rojas, 2015). En éste sentido la violencia es asumida por los actores armados como estrategia y delito, así como también, a modo de recurso y mecanismo para controlar a otros y mantener el terror como elemento movilizador del orden (Baudillard y Morin, 2003), en cuyo caso puede haber variaciones de la violencia que se ejerce, motivo por el cual se hace necesario definir la violencia contra la mujer:

(...) Debe entenderse por violencia contra la mujer cualquier acción o conducta, basada en su género, que cause muerte, daño o sufrimiento físico, sexual o psicológico a la mujer, tanto en el ámbito público como en el privado (artículo $1^{\circ}$ ). Se entenderá que violencia contra la mujer incluye la violencia física, sexual y psicológica, (artículo $2^{\circ}$, ley 1257 de 2008)

En consonancia a lo expuesto William Ospina (1996) considera que toda vejación que se ejecute de forma sistemática y premeditada deja una huella permanente de dolor, de la cual la sociedad y las instituciones son corresponsables de reparar, y antes que nada de comprender para evitar su reproducción. Éste aspecto hace del tema de memoria en el postconflicto una responsabilidad compartida por la sociedad, las comunidades y grupos, las instituciones y especialmente las víctimas, quienes deben transitar del relato a la ejecución de acciones que las empoderen de los procesos de verdad, justicia y reparación. Las mujeres víctimas de la guerra, son coartadas de su posibilidad de expresión bajo la amenaza del desplazamiento, la tortura y la desaparición forzosa, motivo por el cual ellas silencian sus protestas y ejercen liderazgos camuflados bajo otras figuras de poder en la comunidad (Villegas, 2010); en la VCM resultan "especialmente preocupantes [...] los homicidios, amenazas y acosos contra quienes trabajan por los derechos de las personas desplazadas, especialmente lideresas de grupos de mujeres" (ACNUR, 2011, p. 11). Cabe anotar que la coacción de la libertad de expresión es un delito tipificado en el artículo uno (1) de la convención contra la tortura y otros tratos o penas crueles, inhumanos o degradantes; dado que en él se expresa que las periodistas, comunicadoras sociales y las mujeres que ejercen la libertad de expresión no deben ser víctimas de agresiones sexuales u otros actos de violencia de género, ni objeto de amenazas, por efecto de las expresiones u opiniones que difundan.

Estos factores muestran pautas orientadoras para pensar la intervención actual y futura de las personas afectadas por el conflicto armado, tomando en cuenta que dicha afectación es en realidad una poliafectación, en cuyo caso es dable considerar las relaciones entre los efectos negativos de la guerra, transitando desde la mirada clínica-reductora centrada en la comorbilidad, hacia una percepción de conjunto más amplia y relacional, es decir, en torno a eventos emergentes y nuevas formas de pensar, sentir, percibir e intuir el conflicto armado y el postconflicto. La paz es también un tema de salud mental, física y comunitaria, porque implica la resignificación del concepto tradicional de paz sin conflictos, es decir, transitar hacia una noción de paz como inclusión del conflicto e inclusive como posibilidad de confrontación y guerra, lo que implicaría pensar la paz como camino, o que la paz es en realidad una tregua. La mujer tiene un rol determinante en la resignificación de esta creencia, al integrar las calamidades y situaciones 
adversas en la vida de los miembros de la familia y la comunidad, extrayendo de ello aprendizajes que enseña y difunde de forma propositiva. El cambio en la noción de paz es coadyuvante en el proceso de resignificación de creencias catastrofistas acerca de la guerra, y permite a quienes eligen cambiarlas, un mejor estadio de convivencia personal y social.

\section{Patriarcalismo, violencia y exclusión social.}

En Colombia la igualdad entre géneros en el ejercicio del derecho a la libertad de expresión “continúa siendo la excepción, en tanto los grupos históricamente menos favorecidos (...) aún luchan para que se tengan en cuenta sus opiniones y para poder acceder a la información que les concierne" (CDIH, 2011, p. 401), en consecuencia, muchas madres desplazadas al desconocer la norma, vivencian desigualdades importantes en el acceso a los medios para hacer valer sus derechos. Lo anterior implica el aumento de la triple vulnerabilidad adscrita a su condición femenina: ser desplazada, ser mujer y pertenecer a una etnia o grupo cultural, social, política e históricamente segregado (Andrade, 2010; 2011). El desplazamiento forzado instaura la experiencia del no-lugar (Pécaut, 1987) que surte de indeterminación la condición ontológica de la mujer desplazada y de todo su grupo familiar, y aunque esto suele ser muy dañino para la estabilidad y adaptación del grupo, el no-lugar "se constituye [también] en el punto de partida para enfrentar precariamente la realidad de su multi-victimización" (Andrade, 2010, p. 34). A nivel étnico las mujeres más vulneradas son aquellas que representan a sus comunidades, que defienden a su familia, y se movilizan en contra de los abusos de la guerra, motivo por el que suelen ser eliminadas o presionadas a migrar forzadamente (Garzón, 2005; Villegas, 2010).

De ello se deriva que la selectividad en cuanto género, condición social y etnia, "afecte particularmente a los pueblos y comunidades indígenas, los grupos afrocolombianos, los desplazados, las mujeres, la niñez y las personas con discapacidad" (ACNUR, 2008, p. 21). Desde una perspectiva psicosocial la violencia de género contra la mujer concierne a la instrumentalización del conflicto con fines de mantenimiento del orden impuesto, al tiempo que la búsqueda de precedentes desde los cuales dicha lógica cobra sentido a través del ejemplo del sufrimiento imputado en otros; se debe señalar que esta labor busca instalar el miedo como factor de permanencia y legitimidad de la violencia y la impunidad (Barros y Rojas, 2015; Insuasty, Balbín, Bastidas, Carrión, Pineda, y Mejía, 2010). Michel Foucault (1977) señala que las prácticas de control social del cuerpo, fueron posibles a través de dispositivos de mediación y control, que operan en el leguaje y se instalan educativamente por medio de las prácticas de socialización. Aplicado al conflicto colombiano se tiene que el discurso violento subvierte en el sujeto sus posibilidades de liberación, aminorando su voluntad al generar la creencia de que debe ser rescatado o salvado por la misma institución que lo coacciona, escenario en el que se reinstitucionaliza. Por su parte Ignacio Martín-Baró ve en la violencia una intencionalidad destructiva que busca demostrar la superioridad de otro, es decir, que opera a través de la exclusión, misma que en su punto máximo implica la muerte real del otro.

Zeltditch (2001) opina al respecto que en la guerra se tiende a legitimar absurdos como la muerte, la tortura y todo trato degradante con el que se reproduce la lógica de la exclusión, misma que opera bajo el principio de amigo-enemigo, es decir desde los extremos que excluyen que el otro tenga posibilidades de mediación, o que actúe como agente de cambio y transformación social. Por ende, quien legitima la violencia tiende a censurar, constreñir o anular legalmente a otros cuando se trata de defender los principios y/o leyes que permiten la reproducción del ordenamiento político. A estas condiciones de anulación es preciso sumar el proceso de 
deshumanización, del cual la mujer es víctima frecuente en el marco de la guerra. Dicho proceso es viable a través del ejercicio de información contradictoria, violenta y estigmatizadora (Bar-Tal, 1996), que promueve la generación de creencias que destruyen, debilitan o atomizan la fuerza y capacidad de cohesión de los vínculos, redes y solidaridades a nivel comunitario. La investigación en violencia de género ha mostrado la existencia de estas dos tendencias (deshumanización y legitimación), probando que la estructura patriarcal prevalece en los diferentes niveles de organización de lo social (Lerner, 1990; Archila, 2014), y que la exclusión/anulación del género femenino obedece en gran medida a la permanencia de dicha estructura en toda interacción entre géneros.

La violencia contra la mujer (VCM) presenta un tinte patriarcal evidente en el hecho que todas las acciones dirigidas a su destrucción se dan a razón de la instrumentalización de su existencia (Amnistía internacional, 2004; Villegas, 2010), es decir, en función de la des-legitimización de su condición humana (Bar-Tal, 2000), estrategia con la cual se ha aumentado el número de víctimas mujeres, al tiempo que se diezma su posibilidad de participación en el conflicto como agente reconstructor de la paz, sujeto de cambio social y/o mediador eficaz (Wilches, 2010). Quizá el punto neurálgico de este argumento se concentra en la idea que tanto en la guerra como en los procesos de paz, el excluir o limitar la participación femenina, constituyen en sí mismo una modalidad de violencia, que puede acoplarse a lo que Bourdieu llama "violencia simbólica", pero que definitivamente se acerca a lo que Zeltditch (2001) considera es un proceso de legitimidad del absurdo, de segregación y discriminación de la mujer en las estructuras patriarcales del poder. Dicho esto, las dimensiones políticas y culturales del conflicto, muestran que la mujer es notablemente victimizada en diversos niveles y escenarios de lo social (De Zubiría, 2015), siendo la guerra la máxima expresión de esta discriminación. Dicho así, la guerra expresa el patriarcalismo extremo (Langland, 1983), y como tal define la forma como persisten las políticas en la historia, además, de la interpretación de la violencia y conflictos armados (Scott, 2006).

\section{La vulnerabilidad de la mujer en la guerra.}

En la guerra es notable el uso de métodos y herramientas cada vez más tecnificadas para destruir lo vivo, además de creatividad en las formas de tortura y exterminio, especialmente, en los más débiles o sobre aquellos que son señalados como víctimas reales y potenciales (Murueta y Orozco, 2015). Esta situación es visible en el marco del conflicto armado colombiano (Fernández, 2002), y se ha constituido año tras año en una de las formas de asegurar la continuidad de la guerra, y según muchos investigadores, en un modo particular de obtener recursos para financiar las campañas bélicas (Meier, 2007; Restrepo y Aponte, 2009; Kalmanovitz, 2009). Como consecuencia de toda forma de violencia, la humanidad experimenta una contradicción antropoética importante, ya que sus avances tecnológicos "producen a la vez conocimientos, beneficios notables, pero también engendran armas, como las nucleares, primera posibilidad de aniquilar la humanidad" (Baudillard y Morin, 2003, p. 38). En este sentido, muchos actos violentos obtienen legitimidad y en ciertos contextos bélicos son asumidos como necesarios para procurar el cambio social, o a modo de herramienta para la liberación de la opresión bajo condiciones de violencia extrema (Zeltditch, 2001), argumento a través del cual la guerra y los actos de lesa humanidad se legitiman para los violentos (Serrano, 1994; Sabucedo, Grossi y Fernández, 1998).

En Colombia la violencia que ha generado el conflicto armado ha dejado múltiples víctimas y pérdidas, sin embargo, de toda la devastación que el conflicto causa son las mujeres y niñas las

\begin{tabular}{l|l|l|l|l|l|l} 
AGO.USB & Medellín - Colombia & Vol. 17 No. 1 & PP 1 - 323 & enero - junio & 2017 & ISSN: 16578031
\end{tabular} 
más afectadas, motivo por el cual es pertinente considerar que el conflicto armado tiene también una perspectiva de género (Andrade, 2010; Soto, 2014). A partir de ello es claro que esta forma de violencia se constituye en un elemento específico y a la vez transversal al conflicto armado colombiano, que incluso ha sido poco visibilizada por diversos actores sociales e instituciones que generalizan la guerra y la reducen al número de años útiles perdidos, así como a territorios cedidos y detrimentos materiales (Pécaut, 2003; CNMH, 2014); en síntesis cuando la guerra se dirige a la mujer "el significado y las consecuencias que para la salud emocional y reproductiva de las mujeres tienen el conjunto de delitos y atentados contra su dignidad y sus derechos humanos difieren de los sufridos por los varones" (Consejería en Proyectos -PCS, 2004, p. 14), quienes regularmente son sostenidos por la representación social de la estructura patriarcal de la figura masculina (Archila, 2014).

Es preciso mencionar que aunque para muchos investigadores el principal problema del desplazamiento forzado se centra en el territorio (Pécaut, 2003), los imaginarios y representaciones negativos que la guerra provoca y sus daños materiales (Estrada y Espinal, 2014; Sabucedo, Grossi y Fernández, 1998), la disgregación familiar (Segura, 2010; Ordoñez, 2013), los aspectos socio culturales (De Zubiría, 2015), los efectos a la salud mental de las víctimas (Rodríguez, De La Torre y Miranda, 2002; Sayago, 2011; Andrade, et al, 2012; Estrada y Espinal, 2014), las dimensiones políticas y el narcotráfico (Fernández, 2002) o las transformaciones del Estado en nación (Chaparro y Hernández, 2009), la impunidad en los contextos de conflicto (Insuasty, et al, 2010). entre otras orientaciones, todas ellas confluyen en que la violencia ha generado pérdidas irreparables en todos los ámbitos que las extensiones de sus efectos implican, siendo las mujeres, niñas y niños los más afectados por las acciones destructivas de los actores sociales vinculados a la trama violenta del conflicto. La mujer en estos escenarios es victimizada de diversas maneras, y tal como lo afirman Guillerot (2005) y Soto (2014), se convierte en el blanco de acciones terroristas, dada su condición humana, así puede ser utilizada como arma de guerra, reclutada, obligada a servir a otro e incluso a abortar como medida de aseguramiento de su pertenencia a ciertos grupos.

De suyo a menudo las mujeres desplazadas interiorizan la idea de convertirse en una carga o en un problema mayor para otros, y como efecto de ello se afecta su estado psicológico y corporal, además de sus relaciones que tiene externamente a la familia. La mujer desplazada suele cargar con las derivaciones biopsicosociales de una triple vulnerabilidad: sexual, material y psicosomática, que se vincula a otra división más peyorativa, es decir, a la construcción del ser vulnerable por el hecho de ser mujer (género), negra/india/mestiza (etnia) y desplazada (condición).

Ilustración 1: Relación entre vulnerabilidades en la mujer desplazada.

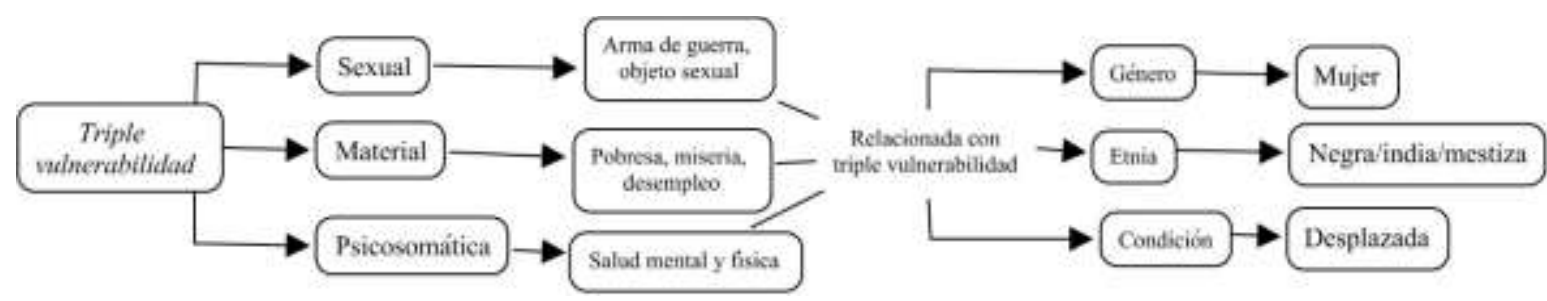

Fuente: Elaboración propia. 


\section{Corporalidad, mujer y violencia.}

El cuerpo de la mujer está signado por la instrumentalización en la guerra, y a partir de ello la mujer deja de ser sujeto para transformarse en objeto y ser deshumanizada, aspecto que para Zeltditch (2001) se constituye en la fuente primaria de todo proceso anulativo. Al respecto Foucault (1977) opina que, a través de la mediación de la medicina, la pedagogía y la economía, el sexo se instaura como un asunto de Estado en el que a nivel social e individual cada persona o grupo es instado a vigilarse, ser vigilado y controlado por otros. Ajustando este planteamiento al conflicto armado, es posible afirmar que la mujer desplazada se reinstitucionaliza en la pedagogía del arma (ser-arma o mujer como arma de guerra); en la medicina a través del control sexual (son obligadas a abortar y ser un objeto sexual (Sayago, 2011), y se controla cuantos hijos debe dar a la "causa"); y en la demografía por medio de la regulación de los nacimientos y abortos (Betancur, 2014). Para los grupos armados la mujer al ser portadora de la vida es también, la reguladora de la reproducción social de la ideología bélica a través de sus hijos, por ello el control de su sexualidad es una estrategia de contención del ejercicio de la libertad (Torres, Barreño, Berbesi, y Sierra, 2010). De suyo en los escenarios de conflicto el cuerpo de muchas mujeres es tomado como instrumento de guerra, siendo abusado por diversos actores que lo toman como objeto de libre uso e intercambio (Villegas, 2010).

Como se ha planteado, la violencia desplegada contra la mujer plantea una contradicción en el ejercicio de la soberanía, equidad y legitimidad del modelo democrático del Estado (Pécaut, 2003), en cuyo caso la democracia se torna autocrática y privativa, objeción que inquieta y viola la integridad de las víctimas, ya que "una democracia es una obra de arte que se crea cotidianamente. No se puede defender, solamente se puede vivir; en el momento que usted la defienda genera una tiranía" (Maturana, 1991, p. 82). En consonancia a lo expuesto, Ignacio Martín Baró (1984) señala que para Betty Friedan (1963) la sociedad occidental ha encerrado a la mujer en un papel coercitivo, limitado, y racionalizado mediante una "supuesta mística femenina" que obedece más a las necesidades de los hombres, que a las de las mujeres mismas. En este sentido la guerra instaura en la relación masculinidad-feminidad códigos del lenguaje, que clausuran la participación de la mujer en la elaboración de propuestas para mediar y aportar soluciones al conflicto armado, lo cual es una limitación a todo nivel, además de otra de las formas de restricción de su papel como agente de cambio. Cabe precisar que en la lógica del exceso de la guerra la mujer es víctima frecuente de abusos y exigencias, ya que tal como lo plantea Foucault (1977) "el soberano no ejerce su derecho sobre la vida sino poniendo en acción su derecho de matar, o reteniéndolo; [lo cual] no indica su poder sobre la vida sino en virtud de la muerte que puede exigir" (p. 164).

Donny Meertens (citado por El Espectador, 2014) considera que el conflicto exacerba los modelos patriarcales de dominación y hacen que la guerra tenga dicha connotación, así la violencia sexual se convierte en violencia específica que aporta a la organización de la violencia en la guerra, la cual es organizada, recurrente y sistemática. De suyo, los impactos sobre las mujeres evidencian constantes en la historia, mismos que son específicos sobre el cuerpo de las mujeres a través de diversas formas de violencia sexual y de género, asimismo existen conmociones en cuanto a sus medios de vida, por efecto del desplazamiento forzado, el despojo de tierras entre otras lógicas anulativas. Meertens opina que el machismo exacerba el conflicto, e instaura un modelo de control social y de despotismo especialmente en sectores rurales dominados por grupos armados. Los procesos de dominación tienen como elemento transversal rasgos patriarcales tales como, castigar y humillar a la mujer públicamente, silenciar su voz,

\begin{tabular}{l|l|l|l|l|l|l} 
AGO.USB & Medellín - Colombia & Vol. 17 No. 1 & PP 1 - 323 & enero - junio & 2017 & ISSN: 16578031
\end{tabular} 
relegarla a un rol, prohibir su participación política, criticar su estilo de vida e imponer otros, etc. De acuerdo con lo expuesto hasta aquí, es posible afirmar que la violencia contra la mujer víctima del conflicto armado, transita por cuatro interacciones interinfluyentes que en conjunto afectan su condición vital y determinan los patrones con los cuales la victimización se torna legítima para los violentos:

- La dimensión territorial-material, orientada a obstruir su desarrollo antroposocial, limitar su capacidad de acceso a bienes y servicios, y a desnaturalizar su rol.

- La dimensión social-comunitaria: que enfoca sus acciones hacia el deterioro de sus vinculaciones, la ruptura de los lazos sociales, el olvido forzado de su historia y la vejación de la memoria.

- La dimensión político-ideológica: cuyo objetivo es aminorar y/o coartar la posibilidad de participación política de la mujer como agente constructor de cambio, imponiendo modos desiguales de interpretar su condición y formas perversas de justificar política e ideológicamente los abusos.

- La dimensión corporal-mental: la cual centra su atención en la generación de efectos nocivos en el orden de lo simbólico, cuya manifestación en la experiencia física, mental -individual y comunitaria- y social de los sujetos se tornan permanentes.

Estos elementos no deben ser dilucidados de forma seccionada, dado que su potencial interpretativo se encuentra en la relación que se hacen de sus múltiples relaciones, más que en la descripción categorial de sus efectos. Quizá el transitar hacia el desarrollo de acciones de reparación en el postconflicto implique a su vez, entender dichas dimensiones como oportunidades, y a partir de ellas orientar los planes y estrategias reparatorias.

\section{Efectos permanentes a la salud mental.}

Es desplazamiento forzado afecta la estabilidad física, mental y social de personas y comunidades, alterando gravemente el principio de realidad y la habitabilidad de los territorios de origen, tránsito y asentamiento (Andrade, 2010). La salud mental de la población victimizada suele ser frágil y con ella emergen nuevos problemas a nivel social-comunitario que suelen ser poco atendidos o evadidos por las víctimas (Sayago, 2011), dado que las personas desplazadas se concentran en cubrir las necesidades básicas y sobrevivir a persecuciones, discriminación e insuficiencia en la seguridad y restablecimiento de derechos por parte de las instituciones, y a menudo son señalados negativamente por las comunidades receptoras. La fragilidad de la salud mental no es solo el correlato directo de la guerra, ya que, es también la enunciación de otras formas de victimización que emergen de los espacios de asentamiento y tránsito de las familias desplazadas. Existen pues, en las victimas síntomas y trastornos psicopatológicos frecuentes como depresión ansiedad, irritabilidad, agresión entre otros, que han sido identificados en diversas investigaciones (Rodríguez, et al, 2002; Méndez, 2007; Andrade, 2010; 2011; Sayago, 2011); estas investigaciones concuerdan en que la mujer se ve más afectada emocional, social y económicamente por el conflicto armado en comparación a los hombres.

Asimismo, Puertas, Ríos, y Del Valle (2006), consideran que existe un impacto diferente en las mujeres cuando se trata de secuelas psicológicas, así pueden aparecen en ellas trastornos mentales comunes (TCM), que a su vez alteran la capacidad de concentración y de atención, la memoria y el sueño; el estudio desarrollado encontró, además: 
(...) una prevalencia de $27,2 \%$ (...) de trastornos mentales comunes en la población adulta (...) En general, 13,6\% (...) de la población encuestada reconoció tener problemas de consumo excesivo de alcohol. Se encontró una asociación entre la prevalencia de trastornos mentales comunes y el tipo de carné usado para acceder a la atención de salud (...) y el sexo (...); dicha asociación persistió aun después del ajuste en función de las demás variables explicativas (p. 324)

Para complementar lo anterior, es preciso señalar que entre los problemas de salud mental frecuentes encontrados en los estudios sobre población desplazada se encuentran: depresión, ansiedad, angustia vital (Fiscó, 2005; Soto, 2014), trastorno de estrés postraumático y estrés agudo (Rodríguez, et al, 2002), trastorno afectivo bipolar (Andrade, Agudelo, Ramírez, y Romero, 2010; Andrade, 2011), entre otros. Dichas patologías mentales suelen tener efectos diferentes en hombres que, en mujeres, siendo más letales en las madres quienes suelen asumir la carga económica, social y afectiva del hogar y su restitución, dada su viudez repentina, la separación de su pareja o por efecto de la disgregación del hogar (Mejía, y Córdoba, 2005; Torres, et al, 2010).

Gerrity, y Flynn, (2000) reiteran que los daños a la salud mental en las victimas de conflictos armados y otras catástrofes suelen ser permanentes, y aunque en muchos casos las personas al huir o resistir sobrevivan y muestren signos de adaptabilidad y robustez, en la mayoría de los casos dicha actitud referencia la remisión de síntomas y problemas mentales que se acumulan, y/o se tornan comórbidos y mucho más dolorosos. En consecuencia, la no-superación de estos eventos traumáticos eleva los estados de ansiedad y torna proclive a las personas a desarrollar patologías mentales y problemas físicos que afectan su calidad y expectativa de vida (Guevara y Barney, 2009). El estado de salud mental de la mujeres víctimas de la guerra es relativamente estable, ya que deben concentrarse en sobrevivir, por lo que suelen remitir u obviar el reconocimiento de sus síntomas; en este proceso la atención y la memoria se ven afectadas gravemente, puesto que para algunas mujeres el olvido forzado, el auto-silenciamiento y la negativa a recordar los hechos victimizantes, se constituyen en herramientas para procesar precariamente la inestabilidad psicológica y ambiental que el conflicto armado suscita (Brito, 2010; Méndez, 2007; Andrade-Salazar, Bedoya-Rodríguez, Escobar-Naranjo, Giraldo-Navarro, y Medina-Gama, 2015), al respecto es relevante señalar la verdadera intención de la recuperación de la memoria:

La memoria no debe sólo recordar y tratar de evitar las formas más graves de violaciones a los derechos humanos, sino que deben ser un rechazo a las nuevas formas de ejercicio abusivo del poder y deben permitir visibilizar otras violaciones generalmente silenciadas - como el acceso a la educación, a la salud, al trabajo, a la igualdad (Instituto Catalán Internacional para la Paz -ICIP, 2014).

Las secuelas psicológicas de la guerra en las victimas de conflictos armados, tienen un criterio de permanencia que se exacerba de forma continua (Toole, 2000). Para el caso de las mujeres desplazadas esto sucede especialmente cuando las condiciones de existencia en el lugar de asentamiento son mínimas, y dichos territorios representan un peligro para la supervivencia y continuidad de la familia (Villa, 2007; CNMH, 2011). Así, la salud mental referencia también las condiciones ambientales que permiten a los miembros desarrollarse de forma integral, situación frágil en personas desplazadas asentadas en lugares peligrosos o con notables falencias en seguridad y convivencia (Andrade, Agudelo, Ramírez y Romero, 2010). La salud mental es un continuum expresado por la Organización Mundial de la Salud (OMS, 2013) a modo de "un estado de bienestar en el cual el individuo es consciente de sus propias capacidades, puede afrontar las 
tensiones normales de la vida, puede trabajar de forma productiva y fructífera y es capaz de hacer una contribución a su comunidad" (p. 1); des así que de acuerdo a una definición positiva de la salud, la recuperación o estabilidad de la salud mental implica la actuación sobre la percepción del bienestar individual y colectivo así como también, el reforzamiento de las habilidades para la vida, especialmente aquellas encaminadas a tramitar adecuadamente los conflictos y responder creativamente ante las dificultades emergentes usando los recursos disponibles y potencializando las habilidades adquiridas.

\section{La mujer y el postconflicto.}

A lo largo de este artículo se ha expuesto la elevada vulnerabilidad de la mujer en la guerra, además de las consecuencias biopsicosociales que el conflicto armado acarrea sobre su humanidad; ahora es momento de hablar del papel de las mujeres en el postconflicto, y no solo en función de las formas consecuentes de la violencia en su vida, sino también considerando su rol fundamental en la construcción de paz y de paces, es decir de tipos de experiencias de paz y dinámicas de pacificación implementadas por las mujeres. Donny Meertens (citada por El Espectador, 2014) opina que la política agraria, por ejemplo, puede y debe tener como guía el acceso a la tierra en la mujer -aun si ésta no cuenta con un compañero afectivo permanente-, lo cual puede impulsar el desarrollo rural y la incursión directa de la mujer en el progreso agrario del país. A ello debe sumarse la posibilidad de ampliar el debate en torno al desarrollo de una política pública que acoja y beneficie también a mujeres excombatientes, es decir, una política de género que descentre la violencia de las víctimas e incluya también a las mujeres victimarias. Otro tópico a considerar es su papel en los procesos de mediación y decisión en acciones de conflictos locales (jueces de paz), escenario en el cual su función conciliadora es vital para avanzar con los diálogos encaminados al perdón.

Para el Instituto Catalán Internacional para la Paz (ICIP, 2014), es necesario construir "infraestructuras de paz" que pueden ser definidas a modo de redes interdependientes "de sistemas, instituciones, recursos, valores y habilidades sostenida por el gobierno, la sociedad civil y las comunidades, que promueve el diálogo y la consulta, previene los conflictos y facilita la mediación pacífica cuando la violencia ocurre en una sociedad" (p. 18), redes que a la vez están conformas por el conjunto de actores sociales y de organizaciones con las estructuras, medios y recursos para construir paz desde sus escenarios de interacción a nivel político y social. Al respecto Clark (2012) considera que la paz no es responsabilidad única del estado y de sus instituciones sino de toda la sociedad en conjunto, así, se constituye en;

Un proceso endógeno de transformación e innovación que para ser sostenible y resiliente sólo puede surgir de las personas, comunidades e instituciones del país, incluidos los más pobres y excluidos, las víctimas, las mujeres, los jóvenes, las poblaciones étnicas, los actores en conflicto, entre otros (ICIP, 2014, p. 19)

La mujer en estos escenarios de construcción de paz puede generar iniciativas de reparación ajustadas a la dinámica de género que permea la violencia, y desde la lógica de su actividad resiliente y de auto-compensación, vislumbrar las necesidades reparatorias a través del reconocimiento de sus experiencias, narrativas y mitologías. Las mujeres desplazadas son garantes de la memoria de la movilización, es decir de los aprendizajes, vinculaciones y racionalidades emergentes del éxodo; asimismo propician a través de la tradición oral el relevo generacional de sus historias, además, de fortalecer a partir de su experiencia los mecanismos de

\begin{tabular}{l|l|l|l|l|l|l}
\hline AGO.USB & Medellín - Colombia & Vol. 17 No. 1 & PP 1 - 323 & enero - junio & 2017 & ISSN: 1657 8031
\end{tabular} 
ajuste a nuevos escenarios de socialización, mismos que pueden servir de base para pensar procesos de adaptación con otras comunidades vulnerables. En este aspecto todo sistema de restauración de sus derechos está sostenido por el respeto a su rol, humanidad e identidad, así como también, en relación a sus capacidades para sobrevivir a la guerra y sus excesos, y de llevar consigo la responsabilidad de reconstituir el hogar y la vida de sus miembros. Para el Instituto de Ciencia Política "Hernán Echavarría Olózaga" (ICP, 2014) la recuperación de la dignidad en las mujeres requiere de una comisión sólida de la verdad, en la que se estudie a profundidad los crímenes sexuales, mismos que han sido poco esclarecidos y escasamente castigados en comparación a otros hechos victimizantes. Al respecto Clara López (citada por ICP, 2014) indica que "en algún momento tenemos que ayudar con el proceso psicológico y psicosocial de las víctimas de quitarse esa etiqueta y de volverse a convertir en ciudadanos, volver a sentirse sujetos y participar activamente" (p. 35)

En consecuencia, se entiende que es necesario ampliar el nivel de participación de las mujeres en los espacios en que se dialoga y se busca la paz, y a través de ellos buscar la reivincación de su dignidad, y de sus derechos económicos, sociales, políticos y culturales. Belén Sanz Luque, directora de la Oficina de Evaluación de ONU Women, considera que equidad e igualdad son básicos para reorganizar el papel de la mujer en el postconflicto, porque disminuyen y eliminan la desigualdad estructural que limita el acceso de la mujer a los espacios de participación y dialogo (Tapella, 2012, Octubre 19); asimismo señala que "en las negociaciones donde participaron mujeres se lograron avances y acuerdos más rápidos y con la inclusión de derechos sociales, económicos y políticos" (La República, Marzo 28 de 2015), y dado su liderazgo positivo se constituyen en agentes de reconstrucción de las paces, es decir, de la filosofía de comprender, integrar, reconocer, dar sentido y superar-resignificar el terror que el otro causó en un momento determinado, lo cual implica hacer las paces superando la dinámica inter-excluyente amigoenemigo, considerando las experiencias personales, colectivas y la cotidianidad de las interacciones, al tiempo que, las experiencias personales y colectivas del otro, es decir a partir de la operatividad practica de los criterios de elección, competencia, aprendizaje y responsabilidad, implicados en todo acuerdo y divergencia.

La mujer es coadyuvante continuo en la educación socio-familiar enfocada en hacer y construir las paces con base en un enfoque diferencial, es decir que incluya las variaciones de género, etnia, discapacidad, víctimas del conflicto armado, a la vez que el reconocimiento, empoderamiento, competencia y responsabilidad de cada actor social en el proceso de construcción de paz y paces (Herrero, 2012). Quizá una de las limitaciones en los procesos de negociación respecto a la paz, es la clara intencionalidad de pensarla en términos de desmovilización, error que se cuenta como transversal a todos los procesos de superación de los conflictos armados en el país. Ante ello una opción posible a dicha limitación, es admitir la necesidad de desarrollar e incluir múltiples políticas que tengan especificidades, tales como, género, acceso a tierras, vulnerabilidad étnica y cultural, restitución de la memoria, reorganización social, resignificación del rol de: ciudadano, combatiente, desplazado, etc., a ello se suma el hecho de proponer una reparación integral e integrada, es decir, policéntrica (de múltiples centros de observancia y creatividad para reintegrar los conflictos antes indisolubles), de características sistémicas en el orden de lo bio-psico-social-antropo-cultural. Se busca que la mujer sea promotora de una paz noética en la que se conjuguen intuición, sentimiento y razón, que logre ser pensada desde la robustez que permitan los acuerdos, y brinde apertura a los diversos actores sociales vinculados. La paz y las paces deben incluir la fragilidad de su operatividad como tregua, la cual se ve sostenida por la responsabilidad compartida de su

\begin{tabular}{l|l|l|l|l|l|l}
\hline AGO.USB & Medellín - Colombia & Vol. 17 No. 1 & PP 1 - 323 & enero - junio & 2017 & ISSN: 1657 8031
\end{tabular} 
sostenimiento y replicabilidad, a la vez que a razón de la trilogía relacional entre intenciónelección-ejecución, aspecto en el que se encuentran implicadas consideraciones bioéticas, el descentralizar el poder para compartirlo, negociar beneficios políticos-económicos, facilitar la toma de decisiones políticas, y el desarrollo de mecanismos transicionales que permitan claridad y flexibilidad en los procesos de verdad, justicia y reparación, además de equidad, transparencia y participación en el manejo y acceso a la información.

Es necesario que la reparación de la mujer tenga un enfoque de derechos en el que también se aborden directrices del Derecho internacional humanitario, respecto a las formas de restituir a las víctimas en el marco de la justicia transicional, así como también, trabajar el tema de reinserción de las mujeres combatientes, enfocado al desarrollo de planes y proyectos de vida realistas para ellas y sus familias, donde se aborde de forma integral e integrada -pluridisciplinarlas diferentes áreas de desarrollo afectadas por el conflicto armado. El empoderamiento, la autonomía y desarrollo de procesos volitivos sólidos pueden ser pautas orientadoras para pensar la intervención y el fortalecimiento de las habilidades para la vida, lo cual redundará en una mejor habilidad de ajuste ante escenarios sociales que las mujeres víctimas y ex-victimarias pueden considerar hostiles, discriminantes o dotados de segregación. Asimismo se requiere de la sensibilización social respecto a la resignificación de la guerra y de sus efectos, lo cual tiene como base la tolerancia, la aceptación y el respeto del otro como legítimo otro en la convivencia, aspecto que Humberto Maturana (1991) denomina amor, lo anterior implica el conocimiento de los hechos es decir, la subversión de la memoria colectiva con miras a conocer la historia contada por víctimas y victimarios, es decir una reconstrucción histórica del sujeto que transforme a su vez lo que se entiende por país, identidad y humanidad.

\section{Conclusiones.}

Si la guerra en Colombia es en gran medida un asunto de género en el que las mujeres fueron víctimas mayoritarias, la paz es también un asunto colectivo que las incumbe como actores principales de denuncia (solicitud de esclarecimiento de los hechos, búsqueda del perdón y restitución simbólica del dolor), elaboración de propuestas y propensión al cambio político. Las mujeres requieren que su voz sea escuchada y que las acciones reparatorias comprendan que los actos de lesa humanidad perpetrados en su contra tienen una connotación de género innegable, dada la vulnerabilidad derivada de las prácticas de maldad de la cual han sido objeto durante más de siete décadas. Por ello es necesario que la especificidad de las violaciones en su contra sea análoga en la especificidad jurídica que tipifica los delitos, en cuyo caso la sociedad y las instituciones están obligadas a reparar integralmente los daños, tomando en cuenta la intensidad de delitos graves como por ejemplo: violaciones a su integridad, obligación a abortar, disgregación familiar, secuestro, instrumentalización (arma de guerra), reideologización militar, silenciamiento, ejecuciones extrajudiciales, reclutamiento forzado, desplazamiento forzado, entre otros crímenes que las constituyen en victimas mayoritarias de los actos de maldad de los violentos.

En relación a lo expuesto cabe anotar que en la mayoría de investigaciones sobre género y violencia los autores usan el concepto de violencia de género y de violencia contra la mujer como sinónimos, no haciendo una clara definición entre las mismas, lo cual excluye de la violencia de género a las identidades LGBT (Lesbianas, Gays, Bisexuales y personas Transgénero), que también se han visto afectadas por las secuelas del conflicto armado. Al respecto existen pocos estudios académicos sobre este tema, aun cuando las organizaciones defensoras de los derechos

\begin{tabular}{l|l|l|l|l|l|l}
\hline AGO.USB & Medellín - Colombia & Vol. 17 No. 1 & PP 1 - 323 & enero - junio & 2017 & ISSN: 16578031
\end{tabular} 
LGBTI denuncian constantes amenazas a esta población por parte de los grupos armados. El tema de la paz en relación a la mujer como actor social de cambio es poco abordado, motivo por el que muchos estudios se orientan más a las causas político-sociales de la migración, que hacia las condiciones psicológicas y culturales de las víctimas, en cuyo caso gran parte de la reparación posterior al desplazamiento también presenta una clara definición en términos de asistencia material y procesos de ajuste social, misma que suele ser vista desde una perspectiva general que escasamente particulariza la condición femenina de las víctimas.

En las mujeres desplazadas esto no solo afecta la capacidad de acceso a servicios de salud mental, sino también la percepción de daño psicológico y de necesidad de asistencia. Al respecto es dable considerar que un posible escenario de reparación en el postconflicto, puede implicar la resignificación de creencias negativas en las mujeres respecto a la asistencia recibida, que pueden ser causa de auto-estigmatización y resistencias a procesos de intervención. En este sentido es preciso determinar que mientras la reparación integral es aquella que reúne y potencializa los recursos disponibles para disminuir los riesgo vitales y las secuelas permanentes del conflicto armado, la reparación integrada, es el conjunto relacional de acciones que enfocadas en resarcir el daño a las víctimas, busca la re-significación de los contenidos y efectos dolorosos de la guerra, o de otros hechos victimizantes, propiciando posibilidades de integración entre medios, recursos, procesos, instituciones, actores sociales y todos aquellos que puedan colaborar con la superación de los daños reales y potenciales. Lo anterior implica asumir que la reparación es un continum, que presenta muchos centros (policéntrico), es decir, que tiene muchas lógicas y emergencias, las cuales se deben ir solventando de forma articulada a los cambios y retos que los escenarios de postconflicto exijan. En este aspecto se requiere de una visión relacional, pluridisciplinar, es decir multidimensional, que comprenda la lógica de la reparación en términos de antagonismo complementario, o sea, en función del acuerdo al cual se llega a través de una perspectiva dialógica en los diálogos sobre la paz.

Las creencias negativas (colaboradora del enemigo, bastión reproductor de la guerra, etc.) e instrumentales (arma de guerra, servidumbre, instrumento bélico, etc.) acerca del rol de la mujer en el conflicto armado, así como los procesos de legitimación del maltrato a su integridad, mantienen y reproducen la vulneración de sus derechos, al tiempo que escalan las diversas formas de maltrato implementadas sobre su humanidad. Por ello a medida que se deslegitima su rol protector-transformador aumentan también los abusos y vejámenes, al igual que la anulación sistemática de la cual es objeto por ejercicio de los diversos actores armados. En torno a ello es preciso mencionar que la resignificación de este proceso devastador requiere incluir en el marco del postconflicto la dignificación de su existencia, bajo perspectivas de vida alcanzables, que implique compromisos de reparación a corto, mediano y largo plazo, la reorganización de las memorias y de su cultura, con las cuales es posible reedificar el sentido de la vida social, política, personal y familiar, además del ejercicio de la función matrística a nivel político, social y comunitario. Para lograrlo es cada vez más necesaria la acción conjunta de personas, familias, comunidades, instituciones y estado, tomando en cuenta que quizá uno de los aspectos más importantes del proceso de reparación es la reorganización real, simbólica e imaginaria de las experiencias de dolor, aspecto que requiere la resignificación de lo inefable (innombrable) que compone la experiencia de sus duelos y perdidas.

Lo innombrable tiene una connotación de terror y angustia vital inseparables del recuerdo de la guerra, que en las mujeres implica una elevada reserva sobre los hechos victimizantes ante la comunidad. De suyo esto conlleva a la preservación de sus vivencias ante situaciones y personas 
que podrían rechazar a priori su condición humana, con base en el temor que suscita el ser cómplice al compartir información. En las victimas el posible sojuzgamiento a causa de su pasado, además del constante choque sociocultural y la discriminación elevan las resistencias ante la integración social y limitan las posibilidades de acceso a redes de apoyo en las comunidades receptoras. Es importante señalar que el silencio de las victimas opera como rezago del silenciamiento impuesto por los grupos armados, y constituye uno de los elementos desencadenantes de problemas adaptativos y de salud mental a nivel de género, al tiempo que el silencio- sirve de estrategia preventiva ante posibles exclusiones comunitarias, acosos de otros grupos armados y señalamientos sociales. Estas situaciones son guías orientadoras que pueden direccionar mejor los procesos de ajuste de estas comunidades a los otros escenarios de socialización, además de abrir el recurso de posibilidades de abordaje de los problemas de adaptación en el postconflicto.

De lo expuesto en las investigaciones es posible realizar una consideración adicional con el fin de globalizar algunos aspectos que tornan viable la comprensión de la violencia en contra de la mujer desplazada a la vez que se constituyen en focos de atención para la reparación integral e integrada en el marco de postconflicto; lo anterior quiere decir que la violencia sociopolítica en contra de la mujer transita por cuatro interacciones complementarias que dialogan entre sí de forma relacional: 1) territorial-material; b) social-comunitaria; c) político-ideológica y d) corporalmental. Dichas relaciones determinan que toda confrontación se dé en diversos planos y niveles de realidad, y que cada uno de ellos presente en el marco de la guerra su propia dinámica y efecto destructivo. De lo anterior se deduce que es cada vez más necesario que la mujer tenga un papel dinámico en los diálogos de paz, y que de ella surjan propuestas que incluyan la reparación de género a partir de una política pública que, si bien se instale en el marco de la justica transicional, no sea flexible ante el castigo de los responsables de los actos de lesa humanidad.

\section{Bibliografía.}

Alta Comisionada de las Naciones Unidas para los Derechos Humanos [ACNUR, 2008]. Informe de la Alta Comisionada de las Naciones Unidas para los Derechos Humanos sobre la situación de los derechos humanos en Colombia. Consejo Económico y Social - Comisión De Derechos Humanos. E/CN.4/2006//009

Alta Comisionada de las Naciones Unidas para los Derechos Humanos [ACNUR, 2009]. Informe anual: Alta Comisionada de las Naciones Unidas para los Derechos Humanos sobre la situación de los derechos humanos en Colombia. A/HRC/10/032

Alta Comisionada de las Naciones Unidas para los Derechos Humanos [ACNUR, 2009a]. Violencia de género y mujeres desplazadas. Recuperado de http://www.acnur.org/t3/fileadmin/Documentos/RefugiadosAmericas/Colombia/Vi olencia_de_genero_y_mujeres_desplazadas.pdf?view $=1$

Alta Comisionada de las Naciones Unidas para los Derechos Humanos [ACNUR, 2011]. Informe de la Alta Comisionada de las Naciones Unidas para los Derechos Humanos sobre la situación de los derechos bumanos Colombia. Recuperado de http:/ /www.acnur.org/t3/uploads/pics/2810.pdf?view=1

Amnistía internacional -AI (2004). Colombia: Cuerpos Marcados, Crímenes Silenciados: Violencia contra sexual contra mujeres en el marco del conflicto armado. España: Editorial Amnistía internacional. 
Andrade, J.A. Agudelo, LF. Ramírez. DC., y Romero, NA. (2010). Relación entre indicadores de problemas de adaptación social y un posible trastorno afectivo bipolar (TAB), en mujeres cabeza de hogar en situación de desplazamiento forzado en la ciudad de Armenia en el 2010. Orbis, 18, 58-81.

Andrade, JA. (2010). Women and children, the main victims of forced displacement. Revista Orbis, 5, 28-53. Recuperado de http://www.revistaorbis.org.ve/16/Art2.pdf

Andrade, JA. (2011). Efectos psicopatológicos del conflicto armado colombiano en familias en situación de desplazamiento forzado reasentadas en el municipio del Cairo en el año 2008. Revista $\quad$ Orbis, 7(20), 111-114. Recuperado de http://www.redalyc.org/pdf/709/70922149005.pdf

Andrade-Salazar, J. A., Bedoya-Rodríguez, L. M., Escobar-Naranjo, M., Giraldo-Navarro, S., \& Medina-Gama, L. M. (2015). Funcionamiento familiar en familias desplazadas, asentadas en el Departamento del Quindío en el periodo 2009-2013. Revista de Psicología GEPU, 6 (1), 106-122.

Archila, M. (2014). Aspectos sociales y políticos de las mujeres en Colombia, siglos XX y XXI. Repositorio Universidad nacional de Colombia.

Baró, I. M. (1984). Acción e Ideología, psicología social. UCA Editores. El Salvador.

Barros, M. A., y Rojas, N. (2015). El Rol de la Mujer en el Conflicto Armado Colombiano. Tesis de maestría sin publicar. Universidad Externado de Colombia.

Bar-Tal, D. (1996). Societal beliefs in times of intractable conflict: The Israeli case. Revista de Psicología Social Aplicada, 6(3), 65-102.

Bar-Tal, D. (2000). Shared belief in a society. Social Psychological Analysis. New York: Sage.

Baudillard, J, y Morin, E. (2003). La violencia en el mundo. Buenos aires, Libros del zorzal editorial.

Betancur, P. (13 de febrero de 2014). Reparar a las víctimas, requisito para la paz en Colombia. Revista Semana. Disponible en http://www.semana.com/opinion/articulo/seis-millones-devictimas-en-colombia-opinion-de-paula-gaviria/377095-3

Brito, D. (2010). El desplazamiento forzado tiene rostro de mujer. La manzana de la discordia, 5 , (1), 65-78. Recuperado de http://manzanadiscordia.univalle.edu.co/volumenes/articulos/Vol5N1/art6.pdf

Cadavid, M. (2014). Mujer: blanco del conflicto armado en Colombia. Analecta política, 4(7), 301318.

Centro Nacional de Memoria histórica -CNMH. (2011). Mujeres y Guerra. Recuperado de www.centrodememoriahistorica.gov.co $\% 2$ Fdescargas $\% 2$ Finformes $2011 \% 2$ FInforme_ mujeresyguerra.pdf\&usg=AFQjCNEAUZnahO-

iA2BKQAIOHRyeLuxqFw\&bvm=bv.103388427,d.eXY

Centro Nacional de Memoria Histórica -CNMH. (2014). Informe General. Capitulo IV: Los impactos y los dan $\square$ os causados por el conflicto armado en Colombia. Disponible en: http://centrodememoriahistorica.gov.co/descargas/informes2013/bastaYa/capitulos/b asta-ya-cap4_258-327.pdf

Chaparro, A, y Hernández, C. (2009). Génesis y Transformaciones del Estado Nación en Colombia: una mirada topológica a los estudios sociales desde la filosofía política. Colombia: Colección textos de ciencias humanas Universidad del Rosario. 
Clark, H. (2012). Putting Resilience at the Heart of the Development Agenda, Discurso ofrecido en la Universidad de Cambridge, 16 Abril 2012. Recuperado de http://www.undp.org/content/undp/en/home/presscenter/speeches/2012/04/16/h elen-clark-putting-resilience-atthe-heart-of-the-development- agenda/

Colciencias (2005). Índice bibliográfico Publindex. Recuperado de https://www. http://publindex.colciencias.gov.co:8084/publindex/docs/informacionCompleta.pdf

Comisión interamericana de derechos humanos -CDIH. (2011). Informe anual de la comisión interamericana de derechos bumanos 2010. Informe de la relatoría especial para la libertad de expresión. OEA/Ser.L/V/II. Doc. 5. 7 marzo 2011.

Consejería en Proyectos -PCS (2004). IMPUNIDAD pongámosle fin. Violencia sexual contra las mujeres en conflicto armado y post conflicto en América Latina. España: Editorial Consejería en Proyectos -PCS

De Zubiría, S. (2015). Dimensiones politicas y culturales en el conflicto colombiano. Departamento de Filosofía. Universidad de los Andes (Bogotá, Colombia). Centro Nacional de Memoria histórica. Recuperado de http://www.centrodememoriahistorica.gov.co/descargas/comisionPaz2015/zubiriaSergi o.pdf

El Espectador. [El Espectador]. (2014, Diciembre 26). "El conflicto armado exacerba el machismo": Donny Meertens. [Archivo de video]. Recuperado de https://youtu.be/ixt2wulYASI

Estrada, DA, y Espinal, E. (2014). El cuerpo: entre la negación, la utopía y la instrumentalización. Revista Curare. 1(1), 61-69

Fernández, E. (2002). El narcotráfico y la Descomposición Política y Social: El caso de Colombia. México: Plaza y Valdés editores.

Fiscó, S. (2005). Atroces realidades: la violencia sexual contra la mujer en el conflicto armado colombiano. Papel Político, 1(17), 119-159.

Foucault, M. (1977). La voluntad de saber. Barcelona, Editorial Siglo XXI

Friedan, B. (1963). La mistica femenina. Nueva York: Norton, 1963.

Garzón, C. E. (2005). Diagnóstico de Género de la población de Soacha, con énfasis en las mujeres desplazadas. Fondo de Desarrollo de las naciones Unidas para la Mujer [UNIFEM].

Gerrity, E. T, y Flynn, B. W. (2000). Consecuencias de los desastres en la salud mental. En: Noji EK (edit.). Impacto de los desastres en la salud pública. Bogotá: Organización Panamericana de la Salud.

Guevara, C, y Barney, F. (2009). Desplazamiento forzado en Florida, Valle del Cauca. Mujeres, territorio y cultura. Revista Cientifica Guillermo de Ockham, 7(1), 57-68. Universidad de San Buenaventura, Sede Cali, Colombia. Recuperado el 15 de julio de 2010 de http:/ / redalyc.uaemex.mx/pdf/1053/105312251005.pdf

Guillerot, J. (2005). La dimensión de género en las reparaciones. Ponencia presentada en el Seminario Internacional Kapañan Warmiñan: Justicia, Género y Reparaciones. Lima, noviembre de 2005. 
Herrero, S. (2012). La educación para la paz desde la filosofía de hacer las paces. Doctorado internacional en paz, conflictos y desarrollo. El enfoque REM. Recuperado de http://www.tesisenred.net/bitstream/handle/10803/119538/sherrero.pdf?sequence= 1

Instituto Catalán Internacional para la Paz - ICIP (2014). Colombia en el posconflicto violento: retos y escenarios para La construcción de la paz. N ${ }^{\circ} 20$ - abril de 2014. Recuperado de http://www.las2orillas.co/wp-content/uploads/2014/05/Per-la-Pau-n20-ESP.pdf

Instituto de Ciencia Política -(ICP, 2014). Entre transición y restauración. Desafíos para la sociedad colombiana en el posconflicto: contribuciones al debate sobre justicia transicional en Colombia. Molano, A (ed.). Fundación Konrad Adenauer-KASColombia. Recuperado de http://www.kas.de/wf/doc/15538-1442-4-30.pdf

Insuasty, A. Balbín, J. Bastidas, W. Carrión, J. Pineda, J., y Mejía, W. (2010). Las víctimas en contextos de violencia e impunidad. Caso Medellin. Instituto Popular De Capacitación -IPC; Fundación Forjando Futuros; Universidad de San Buenaventura Medellín; Comisión Nacional De Reparación y Reconciliación; Personería De Medellín.

Kalmanovitz, S. (2011). El impacto económico del conflicto interno colombiano y un escenario de paz: Universidad de Bogotá Jorge Tadeo Lozano.

Ley 1257 de 2008. Congreso de la república de Colombia.

Lerner, G. (1990). La creación del patriarcado. Barcelona: Editorial Crítica, S.A

Langland, E. (1983). A Feminist Perspective in the Academy: The Difference It Makes. University of Chicago Press, Chicago.

Lozano, J. M. (2005). De patos, gansos y cisnes. Revisiones narrativas, revisiones sistemáticas y meta-análisis de la literatura. Acta Médica Colombiana, 30(1), 1-3.

Maturana, H. (1991). La democracia es una obra de arte. Cooperativa editorial Magisterio.

Meier, R. (2007). ¿Por qué son víctimas las personas desplazadas? La página humanitaria. Colombia: hechos del callejón. Recuperado de http://med.javeriana.edu.co/vidas_moviles/Documentos/victimasdesplazados.pdf

Mejía, A., y Córdoba, Y. (2005). Mujer desplazada cabeza de familia informe final. Desplazamiento forzado en Colombia. Universidad nacional de Colombia. Sede Medellín. Facultad de arquitectura. Escuela del hábitat CEHAP. . Recuperado el 15 de junio de 2010 de http://agora.unalmed.edu.co/desplazados/canal3/proyectos/200501/grupo/MUJER\%20DESPLAZADA\%20CABEZA\%20DE\%20FAMILIA.pdf

Méndez, N. V. (2007). Colombia: Violencias, conflicto armado y resistencias de género: las apuestas de una cartografía de la esperanza. Revista Otras Miradas, Universidad de los Andes Venezuela, 7(1). Recuperado de http:/ / www.redalyc.org/articulo.oa?id=18370105

Murueta, E., y Orozco, M. (2015). Alternativas frente a la violencia social desde la teoría a la praxis. En: Psicología de la violencia, causas, prevención y afrontamiento. $2^{a}$ edición. México, Editorial el Manual Moderno.

Ordoñez, A. (2013). Aproximación Psicosocial a la Victimización y sus Implicaciones en las relaciones Familiares. Tesis de grado. Facultad de psicología de la Universidad de San $\begin{array}{lll}\text { Buenaventura Cali. Recuperado de } & \end{array}$ 
http://bibliotecadigital.usbcali.edu.co/jspui/bitstream/10819/1379/1/Aproximaci\%C 3\%B3n_Relaciones_Familiares_Ord\%C3\%B3nez_2013.pdf

Organización mundial de la salud -OMS. (2004). Invertir en salud mental. Departamento de Salud Mentaly Abuso de Sustancias, Organización Mundial de la Salud, Ginebra. Recuperado el 10 de junio de 2010 de http://whqlibdoc.who.int/publications/2004/9243562576.pdf

Organización Mundial de la Salud -OMS. (2013). Salud mental: un estado de bienestar [en línea].

Recuperado de http://www.who.int/features/factfiles/mental_health/es/

Ospina, W. (1996). ¿Dónde está la franja amarilla? Colombia: Colección Milenio

Pécaut, D. (1987). Orden y Violencia. Bogotá: Siglo XXI editores.

Pécaut, D. (2003). Violencia y Politica en Colombia: Elementos de reflexión. Medellin: Hombre Nuevo Editores.

Puertas, G. Ríos, C., y Del Valle, H. (2006). Prevalencia de trastornos mentales comunes en barrios marginales urbanos con población desplazada en Colombia. Rev Panam Salud Publica, 20(5), 324-30.Recuperado de http://iris.paho.org/xmlui/handle/123456789/7912

Restrepo, J., y Aponte, D. (2009). Guerra y violencias en Colombia Herramientas e interpretaciones. Bogotá: Editorial Pontificia Universidad Javeriana, 2009.

Rodríguez, J. De La Torre, A., y Miranda, C. (2002). La salud mental en situaciones de conflicto armado. Biomédica; 22, 337-46

Ruta Pacífica de las Mujeres - RPM (2013). La verdad de las mujeres en el conflicto armado en Colombia. Tomo II. Disponible en: http://centromemoria.gov.co/wpcontent/uploads/2013/11/La-verdad-de-las-mujeres-Tomo-II.pdf

Sabucedo, J. M., Grossi, J. \& Fernández, C. (1998). Los movimientos sociales y la creación de un sentido común alternativo. En P. Ibarra \& B. Tejerina (Eds.), Los movimientos sociales: transformaciones políticas y cambio cultural (pp. 165-180). Madrid: Trotta

Sayago, J. (2011). Desplazamiento forzoso en Colombia: expulsión y movilidad, dos dinámicas que interactúan. Universidad nacional de Colombia. Tesis de grado. Recuperado de: http://www.bdigital.unal.edu.co/5901/1/tesis_sayago_Agosto_21.pdf

Scott, J. (2006). Joan Scott y las políticas de la historia. Cristina Bordéiras (ed.). Barcelona: Icaria Editorial

Segura, E. (2010). Impacto del conflicto armado interno en la familia colombiana. Estudios en Derecho $\quad y \quad$ Gobierno, 3(2). Recuperado de http://portalweb.ucatolica.edu.co/easyWeb2/files/54_10644_conflicto-armado-yfamilia.pdf

Serrano, E. (1994). Legitimación y racionalización. Weber y Habermas: la dimensión normativa de un orden secularizado. Barcelona: Anthropos.

Soto, L. J. (2014). La narración oral como herramienta en la construcción de la memoria colectiva de la violencia. Experiencia con mujeres víctimas de desplazamiento forzado en Colombia. Revista colombiana de ciencias sociales, Fundación Universitaria Luis Amigó, 5(1). Recuperado de http://www.funlam.edu.co/revistas/index.php/RCCS/article/view/1206 
Tapella, E. [Esteban Tapella]. (2012, Octubre 19). Entrevista a Belén Sanz. [Archivo de video]. Recuperado de https://www.youtube.com/watch?v=BF8haJXNxN4

Toole, M. (2000). Emergencias complejas: refugiados y otras poblaciones. En: Noji EK (edit.). Impacto de los desastres en la salud pública. Bogotá: Organización Panamericana de la Salud; 2000.

Torres, Y. Barreño, J. Berbesi, D. Y, y Sierra, G. M. (2010). Indicadores de trastornos de salud mental en población desplazada, Colombia, 2010. Universidad CES. Recuperado de http://onsm.ces.edu.co/uploads/files/11201950_Informe-tamizajes-poblaciondesplazada.pdf

Villa, J. D. (2007) Si no fuera por Dios, nosotros ya nos hubiéramos muerto" Víctimas, reconciliación y religión. Theologica Xaveriana. 57(164), 565-590.

Villegas, M. (2010). La violencia sexual como arma de guerra. Agencia catalana de cooperación Quaderns De Construcció De Pau, 15, 1-17. Recuperado de http://escolapau.uab.es/img/qcp/violencia_sexual_guerra.pdf

Wilches, I. (2010). Paz con género femenino. Mujeres y construcción de paz. Recuperado de http://www.educacion.mzc.es/wpcontent/uploads/Documentos/SATVG/12WILCH ES.pdf

Zeltditch, M. (2001). Theories of legitimacy. En J. Jost \& B. Major (Eds.), the Psychology of Legitimacy. Emerging perspectives on ideology, justice, and intergroup relations (pp. 33-53). Cambridge: University Press. 